\title{
MRS reports election results for 2020
}

\author{
mrs.org/governance
}

$\mathrm{M}$

embers of the Materials Research Society (MRS) have elected a vice president (who will serve as president in 2021), a secretary, and five directors to join the 2020 MRS Board of Directors. The Board is composed of four elected officers and up to 18 board members, 15 of whom are elected by the membership. A fifth officer (treasurer) is appointed yearly.

The MRS Board of Directors is the highest governing body of MRS, responsible for establishing policy, monitoring progress of the society toward its long-term goals, and setting the strategic directions for the activities of the society, including its meetings, publications, interactions with government agencies, and cooperative efforts with other professional societies.

The officers of the Society are the president (who serves as chair of the Board), the vice president (who is also the president-elect), the secretary, the treasurer (a position appointed by the Board of Directors), and the immediate past president. All members of the Board, except the president, serve on one of six Board Committees: External Relations, Finance, Governance, Nominating, Operational Oversight and Audit, and Planning. Each committee is responsible for formulating policy and strategy issues in their specific areas for full Board consideration.

Terms of office expire at the end of the year indicated in parentheses. The asterisk $(*)$ designates those who are newly elected. The annual election ended August 31, 2019.

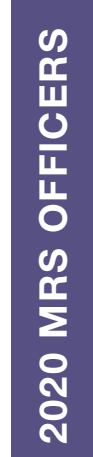

\section{President}

Matt Copel

IBM T.J. Watson Research Center

Immediate Past President

Michael R. Fitzsimmons

Oak Ridge National Laboratory

and The University of Tennessee

Vice President (President-Elect)

* Cherie R. Kagan

University of Pennsylvania
Secretary

* Dawnielle Farrar-Gaines

Johns Hopkins University

Treasurer

Shenda Baker

Synedgen Inc.

Executive Director

Todd M. Osman

Materials Research Society

* Newly elected.
Griselda Bonilla (2020)

IBM T.J. Watson Research Center

* Leonard J. Brillson (2023)

The Ohio State University

* Kristen H. Brosnan (2023)

GE Global Research

* Coray M. Colina (2023)

University of Florida

* Catherine Dubourdieu (2023)

Helmholtz-Zentrum Berlin/

Freie Universität Berlin

Sarah Heilshorn (2021)

Stanford University

Frances A. Houle (2021)

Lawrence Berkeley

National Laboratory

Mônica Jung de Andrade (2021)

The University of Texas at Dallas

Alan G. MacDiarmid

NanoTech Institute

Sergei V. Kalinin (2021)

Oak Ridge National Laboratory

Center for Nanophase

Materials Sciences
Kisuk Kang (2021)

Seoul National University

Paul C. McIntyre (2020)

Stanford University

**Linda S. Schadler (2021)

The University of Vermont

Christopher A. Schuh (2020)

Massachusetts Institute

of Technology

Rachel A. Segalman (2020)

University of California,

Santa Barbara

* Ting Xu (2023)

University of California,

Berkeley

Yusheng Zhao (2021)

Southern University

of Science and Technology

Ehrenfried Zschech (2020)

Fraunhofer Institute for

Ceramic Technologies

and Systems

*Newly elected.

** Appointed June 2019

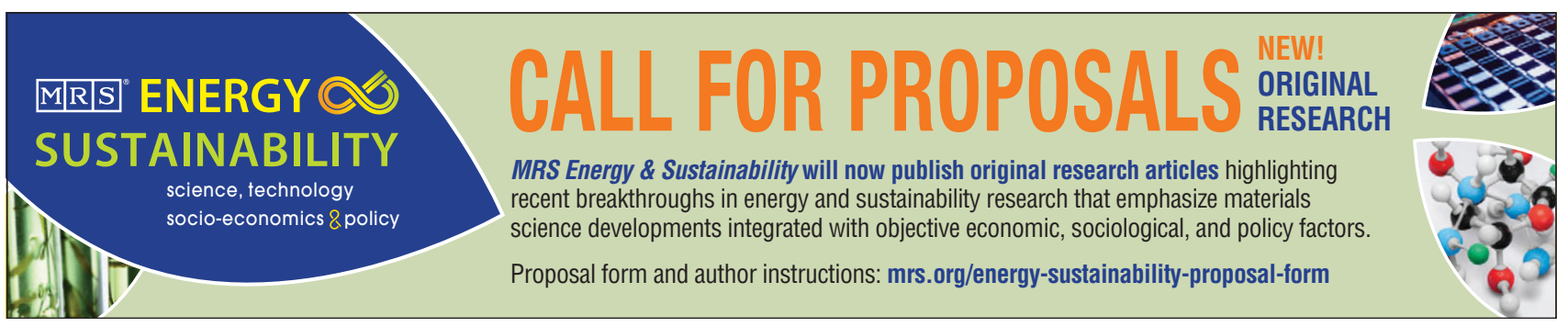



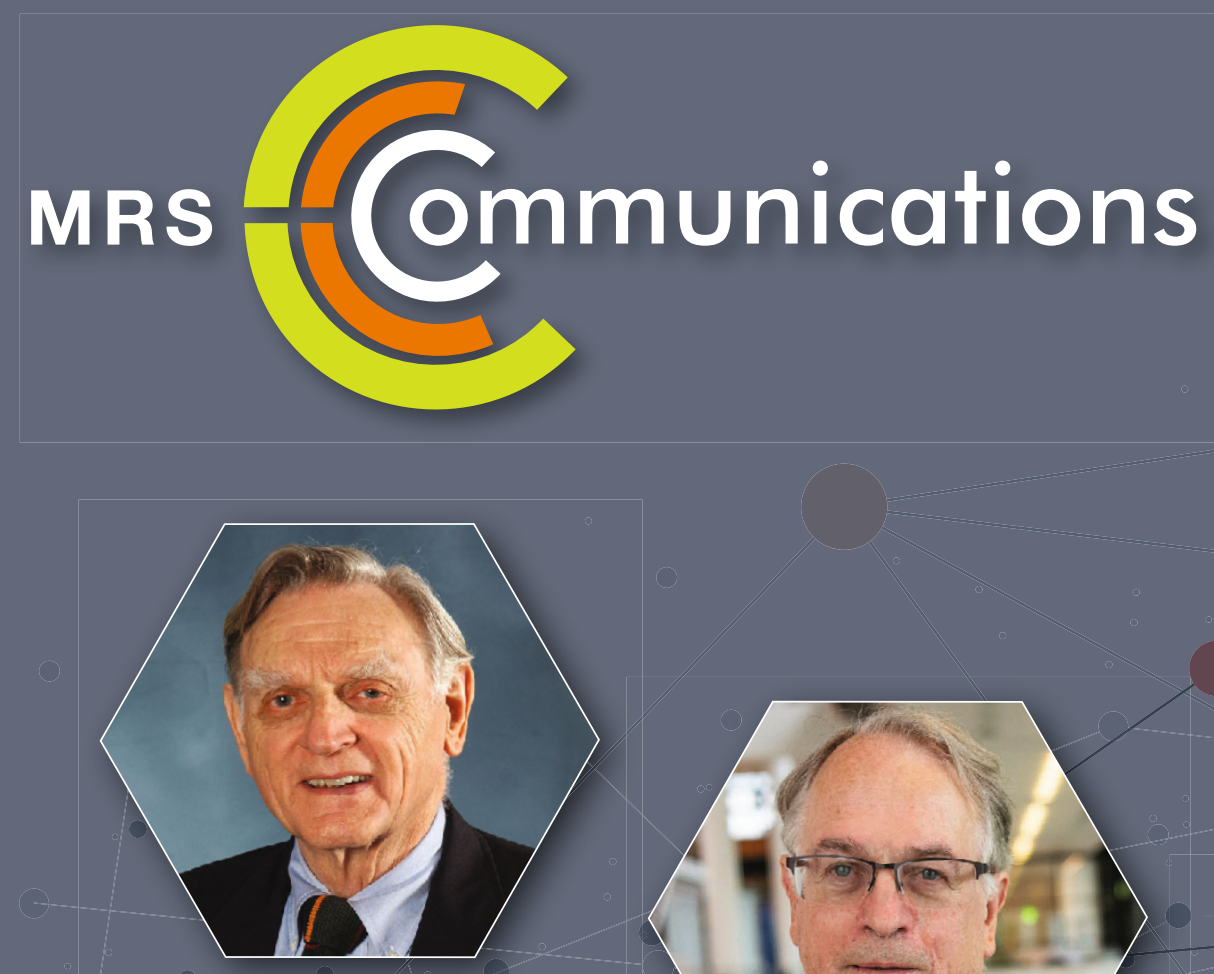

John B. Goodenough $\star$ Nobel Prize in Chemistry 2019

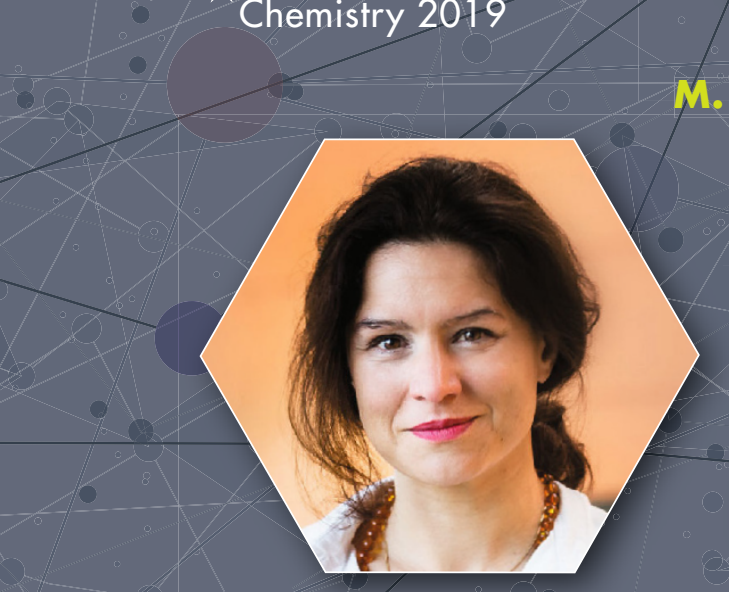

Clara Santafo

2018 MRS Communications Lecture Award

\section{Nominate a colleague today.}

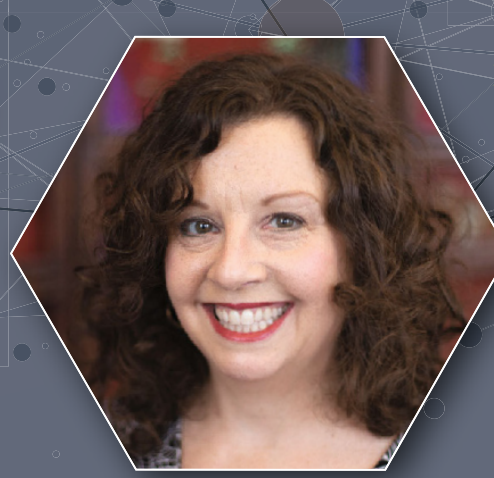

Sharon C. Glotzer - 2017 MRS Communications Lecture Award

\section{Publish}

alongside experts in your field!

2020 MRS COMMUNICATIONS LECTURE

DEADLINE: JANUARY 17, 2020

Timothy J. Bunning 2019 MRS Communications Lecture-Award

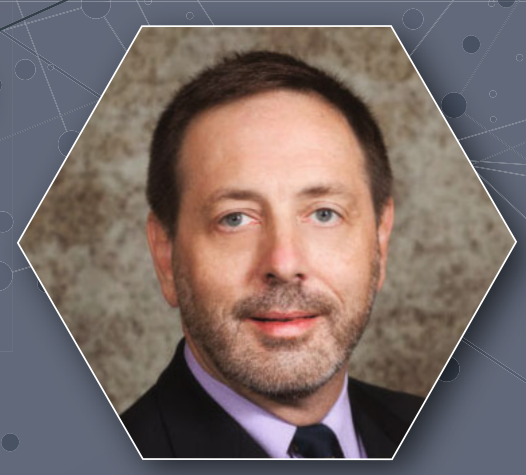

David C. Martin

2016 MRS Communications Lecture Award 